\title{
Futebóis - da horizontalidade epistemológica à diversidade política
}

\author{
Footballs - from the epistemological horizontality \\ to the political diversity
}

\author{
Arlei Damo \\ Universidade Federal do Rio Grande do Sul (UFRGS), Porto Alegre/Brasil \\ Doutor em Antropologia, UFRGS \\ arleidamo@gmail.com
}

\begin{abstract}
RESUMO: Este ensaio tem por objetivo recuperar o contexto no qual o conceito de "futebóis" foi forjado e de pensar seus usos possíveis no presente e no futuro dos estudos esportivos. Primeiramente, argumento que o conceito foi usado em um momento no qual a produção em ciências sociais sobre a temática esportiva encontrava-se em expansão, procurando se estabelecer enquanto um polo discursivo próprio. Sugiro que, naquela ocasião, a noção de futebóis objetivava promover uma horizontalidade epistemológica, não devendo as ciências sociais se aterem ao futebol de espetáculo. Atualmente nos encontramos noutro contexto, marcado pela contestação da proeminência androcêntrica e pela renovação do campo, sob diferentes aspectos. Se há duas décadas a noção de "futebóis" ajudou a perceber o amplo espectro de práticas futebolísticas pesquisáveis, nota-se no presente uma mobilização crítica no sentido de discutir as implicações políticas que perpassam a definição de temas e as formas de dialogar com certos movimentos esportivos e políticos que defendem as práticas não hegemônicas. Sugiro que esta mudança de perspectiva está em curso - atestada, por exemplo, pelo interesse notável pelo futebol de mulheres - e tem a ver também com mudanças ocorridas no futebol de espetáculo, as quais contribuíram para afastá-lo das classes populares, razão principal pela qual o futebol tornou-se um tema legítimo - ainda que periférico - no campo das ciências sociais brasileiras.
\end{abstract}

PalaVRAS-CHAVES: Futebóis; Estudos esportivos; Diversidade; Política; Futebol de mulheres.

ABSTRACT: This essay aims to recover the context in which the concept of "footballs" was forged and to think of their possible uses in the present and future of sports studies. Firstly, I argue that the concept was used at a time when social science production on the sport theme was expanding, seeking to establish itself as a discursive pole of its own. I suggest that, at that time, the notion of footballs was intended to promote an epistemological horizontality, and the social sciences should not be attached to spectacle football. We are now in another context, marked by the challenge of androcentric prominence and the renewal of the field of research, under different aspects. If the notion of "footballs" helped to understand the wide range of searchable football practices for two decades, a critical mobilization is now being made in order to discuss the political implications of defining themes and ways of talking to certain movements sports and politicians who defend non-hegemonic practices. I suggest that this change of perspective is under way - attested, for example, by the remarkable interest in women's football - and it has to do with changes in spectacle football, which have helped to keep it away from the popular classes, which football has become a legitimate - although not very prestigious - subject in the field of Brazilian social sciences.

KEYwORDS: Footballs; Sports Studies; Diversity; Politics; Women's Football. 


\title{
INTRODUÇÃo
}

\author{
Yngrid, no intervalo do jogo, havia se esparramado em uma das \\ cadeiras embaixo do toldo da organização do evento, sem sequer \\ solicitar permissão. Insistente, começou a dizer em voz alta: \\ - Quero uma cervejaaa. Eu aqui nesse calor, e nem uma cervejinha \\ prá tomá. \\ Clarisse, sua técnica, interveio: \\ - Primeiro vai corrê! \\ Descontente, voltou-se então para um dos organizadores do evento: \\ - E o meu latão, professor? \\ O organizador alegou só terágua, no que Yngrid contestou rapidamente: \\ - Água é pro banho!
}

Mais que Barbies e ogras, adaptação de texto de Cláudia Kessler, p. 308.

Quando da primeira utilização do termo futebóis, lembro-me de ter consultado os dicionários para saber se o vocábulo tinha registro, pois assim me pouparia a invenção de um neologismo que soava estranho. Embora seu uso fosse escasso, constava nos dicionários, restando-me então justificar o seu emprego conceitual, o que não seria complicado para um antropólogo habituado aos mantras disciplinares, em especial das tradições culturalistas, que fazem referência constante à diversidade e ao pluralismo. No espectro da antropologia, estas são questões básicas, abordadas nas aulas introdutórias, junto com os conceitos de etnocentrismo e de relativismo, razão pela qual não parecia ser necessária uma longa arguição. Além disso, a pretensão circunscrevia-se, no essencial, à demarcação da especificidade do objeto do qual me ocupava, a formação de jogadores profissionais, em relação à diversidade de práticas futebolísticas. Com a publicação da tese em livro a discussão mudou de lugar e, aparentemente, adquiriu mais visibilidade, mas o deslocamento não implicou qualquer refinamento conceitual ou justificativa complementar.

Embora poupado de críticas que seriam pertinentes, não pretendo desperdiçar esta oportunidade para aprimorar o uso original da noção de futebóis. Depois de mais de uma década, tendo a ideia sido assimilada por outras produções - não o termo, em si, mas a ideia de diversidade nele embutida - e já deslocado do propósito original, creio mais frutífero mesclar um relato sobre as circunstâncias da emergência do conceito com inquietações atuais. Trata-se de uma estratégia 
para retomar certos dilemas em relação à produção em ciências sociais sobre o tema, que acredito não terem sido apenas meus, com impasses do presente acredito serem igualmente partilhados, em linhas gerais, pelo menos.

$\mathrm{Na}$ origem, a noção de futebóis prestou-se como recurso metodológico, estritamente acadêmica, portanto, a dizer que o mundo do futebol era mais amplo e diversificado do que meu objeto de investigação ou mesmo daquilo que nossa então insipiente produção centrada no futebol de espetáculo fazia crer. Agora, seu uso está adquirindo conotações mais próximas à política, o que não fere o seu propósito, afinal a noção de diversidade que nele encontra-se embutida é uma ferramenta útil a ambas as frentes. De qualquer sorte, o emprego original pretendia, além de demarcar fronteiras, justificar um horizontalismo epistemológico ofuscado pela produção acadêmica ainda muito próxima da agenda da crônica esportiva. Este panorama foi sendo alterado, pela multiplicação de produções acerca do futebol de várzea e de mulheres, sobretudo, mas ainda tem muito que avançar, inclusive do ponto de vista teórico.

O texto está subdividido em quatro partes, as duas primeiras tratando, basicamente, das circunstâncias em que a noção de futebóis foi gestada, com alguns comentários breves sobre seus limites. Nas duas partes seguintes sugiro que o campo de estudos esportivos passa por um momento de inflexão, com a emergência de novas temáticas e a superação de certos marcos norteadores das primeiras décadas de produção, nas quais o futebol de espetáculo foi o centro das atenções e predominaram temas veiculados à cultura e à sociedade brasileira. Este futebol passou por mudanças expressivas, afastando-se das influências populares, razão pela qual havia sido incorporado às ciências sociais na década de 1980 . Então, há que se repensar nossos referencias, e por sorte isso ocorre num momento em que outros futebóis passam a adquirir maior visibilidade acadêmica.

\section{Do óPIO DO POVO AO óBVIO}

Amadorismo e profissionalismo estiveram entre as categorias analíticas mais utilizadas no espectro da produção acadêmica brasileira até o início da década de 2000, embora elas não sejam o resultado desta produção, antes a extensão - e em 
parte o refinamento, mas apenas em parte - de um uso ostensivo realizado por historiadores amadores, memorialistas e amplamente consagrado pelo próprio campo futebolístico. Se observarmos a bibliografia das décadas de 1980 e 1990, veremos que, além de Universo do futebol (1982), de Roberto DaMatta, há outras referências constantes, como é o caso dos livros de Thomaz Mazzoni (1950) e de Mário Rodrigues Filho (2003[1964]), ambos jornalistas diretamente implicados no processo de profissionalização e, portanto, tendo uma visão triunfalista deste processo - sobretudo Mário Filho.

Outro livro que merece destaque é $O$ pontapé inicial - memória do futebol brasileiro (1990), de Waldenyr Caldas. Note-se, antes de qualquer crítica, que o próprio Caldas utiliza o termo "memória" no complemento do título, e não sem motivos, afinal as principais fontes - mas não únicas - são justamente Mazzoni e Mário Filho. ${ }^{1}$ Essas três narrativas - a de Caldas como uma memória de segunda mão - se ocupam do debate entre defensores do amadorismo e do profissionalismo, um tipo de disputa importada, como o próprio jogo, e atinente à classe dirigente - portanto, situada no andar de cima. Não se pode negar que os desdobramentos dessa contenda, favorável ao profissionalismo, contribuiu para o afrouxamento das restrições à participação de atletas oriundos das classes populares, em particular de negros e mulatos, nos clubes das elites que mais tarde haveriam de se tornar a elite clubística. Todavia, a maneira como os jogadores ou mesmo o público participou desta refrega ainda é pouco conhecida, embora tenhamos alguns trabalhos que se aproximaram deste objetivo difícil de ser atingido dada a dificuldade de localizar documentos retratando os pontos de vista de pessoas comuns. ${ }^{2}$

Havia bons motivos para que a narrativa "profissionalista" - que faz apologia do profissionalismo - fosse assimilada quase sem ressalvas nas décadas de 1980 e 1990, quando se produziram as primeiras dissertações e teses com viés

\footnotetext{
${ }^{1}$ Outra hipótese plausível é de que o autor, sendo sociólogo e não historiador de formação, tenha evitado usar o termo "história", em que pese seu livro - originalmente uma tese visando a livre-docência na Escola de Comunicação e Artes da USP - tenha uma abordagem em diacronia, cobrindo o período de 1984 a 1933.

${ }^{2} \mathrm{O}$ trabalho de Santos (2010) é um dos que mais se aproxima desta abordagem ao recuperar a história do Vasco da Gama e da construção do estádio de São Januário, porque mantém um olhar aberto às diferentes vozes mobilizadas pelo processo. Apesar do esforço, também neste caso há obstáculos em relação às fontes.
} 
acadêmico, ainda dependentes dos memorialistas, mas a história da ascensão dos negros e mulatos tem outros matizes, bem mais intrincados do que um mero desdobramento do embate entre dois grupos de dirigentes conservadores. Um dos subprodutos desta narrativa memorialista foi a fixação de certos eventos em marcadores históricos, como se eles tivessem representado, efetivamente, cortes abruptos e radicais.

A concertação entre defensores do amadorismo e do profissionalismo foi um evento importante, mas é equivocado pensar que tenha implicado em mudanças radicais, da noite para o dia, em termos da organização do futebol ou, ainda menos provável, da carreira dos jogadores, nas formas de torcer e, sobretudo, para além das praças nas quais os embates haviam se consolidado cidades do Rio de Janeiro e de São Paulo, especialmente. Mesmo que nos detenhamos na questão da gestão do futebol, o suposto êxito do profissionalismo precisa ser matizado, não devendo ser tratado de forma linear, de cima para baixo, do centro para as periferias e assim por diante. De mais a mais, observando o processo numa temporalidade mais alongada, que inclui a década de 1980, nota-se como os termos amadorismo e profissionalismo ressurgem nos discursos de dirigentes, cronistas e torcedores, embora com sentidos diversos daqueles vigentes na primeira metade do século. Como são categorias nativas de uso recorrente, o mais indicado é observá-las à certa distância, pois assim se pode acompanhar melhor as flutuações em termos de significados, como tem sido a tendência contemporânea. ${ }^{3}$

Como os primeiros trabalhos acadêmicos surgiram no eixo Rio de JaneiroSão Paulo, tomou-se como parâmetro as datações e mesmo os embates registrados pela crônica esportiva desses estados, em particular a das capitais, não apenas como fontes, senão como verdades. Gilmar Mascarenhas (2001) foi um dos pioneiros a contestar, de forma consistente, a narrativa hegemônica que até então tomava o futebol desse eixo como um modelo nacionalmente generalizável, com cronologias, personagens e sentidos. Fátima Antunes (1992) aportou uma importante contribuição ao investigar o futebol de fábrica, mostrando um cenário

\footnotetext{
${ }^{3}$ BURLAMAQUI, 2013; GIGLIO, 2018.
} 
paralelo de práticas e de tensões àquele descrito pelos que se atinham aos embates entre as elites dirigentes. No futebol de fábrica ganhavam importância as querelas entre lideranças políticas e esportivas, entre diferentes concepções de gestão do esporte por parte de militantes de esquerda e os embates destes contra a classe patronal. Antônio Jorge Soares (2001) foi ousado ao levantar uma controvérsia acerca das fontes até então utilizadas, contestando a perspectiva de Mário Filho acerca da participação dos negros no futebol, embora suas críticas possam ter sido excessivas. Fábio Franzini $(2000 ; 2005)$ foi o responsável por recuperar a prática do futebol por mulheres, a partir de documentos recolhidos em paralelo à sua pesquisa principal. Esses não são os únicos casos, mas são ilustrativos de um processo de deslocamento das narrativas produzidas no espectro das ciências sociais daquelas vigentes no senso comum midiático ou nos memorialistas.

A ruptura com as categorias dicotômicas amadorismo/profissionalismo não foi abrupta e nem o produto de uma contribuição individual e isolada. 0 fato de que em certo momento tenha me ocupado disso não é obra do acaso, tampouco foi um evento pontual, como as publicações às vezes fazem parecer. Antes de recuperar um pouco mais sobre o mal-estar em relação ao par dicotômico, convém reiterar, uma vez mais, a diferença entre a maneira como ele vinha sendo utilizado até a década de 2000 e uma abordagem contemporânea, que tomam os embates como objeto de investigação, fazendo as categorias em questão corresponderem aos seus respectivos contextos, sentidos e agentes históricos. 0 que se faz agora é uma espécie de história das mentalidades das elites dirigentes e dos embates das e através das agências que governam os esportes de espetáculo, mantendo certa distância delas e tratando-as com a bibliografia devida. Outrora se replicava esses embates, transformando, sem mediação, as categorias em disputa pelos agentes em categorias explicativas e, não raro, como ocorreu com certas leituras da obra de Mário Filho, reproduzindo um alinhamento de perspectivas. ${ }^{4}$

0 fato de ter realizado trabalho de campo entre os torcedores dos clubes porto-alegrenses - notadamente os gremistas - e estar atento à diacronia, percebi

\footnotetext{
${ }^{4}$ Note-se, como ilustração, que a excelente tese convertida em livro do historiador Leonardo Pereira (2000), cita Mário Filho e Thomaz Mazzoni na sessão "Bibliografia", ao lado de Hobsbawm, Wahl e Sevcenko, e não na sessão de "Memorialistas", onde constam nomes como os de Coelho Netto, Gilberto Amado e Floriano Peixoto Corrêa.
} 
já à época da dissertação de minha autoria (1998), certos desconfortos com as narrativas até então hegemônicas, a começar pela cronologia. É certo que no Rio Grande do Sul - mais precisamente em Porto Alegre, talvez Pelotas e Rio Grande houve tensões entre defensores do amadorismo e do profissionalismo, com a pacificação no fim da década de 1930, mas isto não era essencial para a compreensão da história de como se construíram as rivalidades clubísticas. Essas tinham outros marcadores importantes, como os de território, classe social e etnia/raça.

Um artigo de Julio Frydenberg (1997), veio ao meu encontro, por tratar dos primórdios do futebol no continente sul-americano com mais ênfase na popularização do que na sua difusão. Há que se considerar as diferenças em relação aos respectivos processos, que podem ter influenciado no fato das bibliografias nacionais - brasileira e argentina, neste caso - terem seguido caminhos distintos. De qualquer sorte, a popularização força a pensar mais verticalmente, sobre a disseminação da prática do jogo e de agremiações correspondentes - foco do artigo de Frydenberg - enquanto a difusão conduz a pensar em termos geográficos, algo compreensível para o caso brasileiro. Observando-se, mais tarde, o conjunto do livro de Frydenberg (2011) sobre o mesmo tema, nota-se que apenas um dos dez capítulos trata da disputa entre amadorismo e profissionalismo. Já $O$ pontapé inicial, de Caldas, que talvez seja a comparação mais pertinente, dedica praticamente $70 \%$ às rusgas entre os dirigentes de clubes e federações.

Embora os clubes sejam tratados como instituições na abordagem de Frydenberg, o enfoque recai sobre o modo como eles foram construídos a partir da adesão popular e não pela perspectiva de seus dirigentes - neste último caso a tendência é enfatizar a aquisição do patrimônio, das mudanças estatutárias, dos embates políticos, da distribuição de títulos honoríficos e um extenso repertório de autocelebrações características das elites. Não creio que essas diferenças de abordagem devam ser contabilizadas apenas como efeitos da narrativa de Mário Filho, mesmo porque, não se deve jamais esquecer, boa parte dos impactos de sua obra são tributáveis ao "Prefácio" que acompanha a obra desde sua segunda edição, de ninguém menos do que Gilberto Freyre, o responsável por introduzir a 
questão dos estilos de jogo, outra modalidade de narrativa proeminente entre nós, brasileiros, até recentemente. ${ }^{5}$

Na dissertação, cujo ponto de partida foi a categoria "identidade/imaginário social" e a de chegada foi o "pertencimento clubístico/coletivo", me desvencilhei melhor de Mário Filho do que de Gilberto Freyre, ainda que por uma via acidental. Tive acesso fácil ao texto de Gilberto Freyre - e, claro, um dos cinco capítulos da dissertação abordaria os estilos de jogo - mas ao livro de Mário Filho as referências haviam sido indiretas. ${ }^{6}$ A história da gestão do futebol, que era, basicamente, a que tínhamos disponível, teria de ser outra coisa, algo próximo à história das elites, se aplicada exclusivamente ao futebol de espetáculo - mas sendo possível escrever também uma história da gestão dos clubes de várzea, talvez a orientação teórica devesse ser outra.

Embora não tivesse, na ocasião, a convicção do presente - ou tivesse mais dificuldade de justificá-la, quem sabe - estava claro que, para entender o futebol como uma prática profissional, por ocasião da pesquisa visando a tese de doutorado, iniciada em 2001, havia que orientar o debate a partir de referências outras que não aquelas utilizadas quando abordara a questão do torcer identidades e alteridades clubísticas. Em ambos os casos, estava clara também a necessidade de acentuar a distância entre o discurso antropológico e o discurso midiático, um objetivo coletivo, ainda que difuso, ao longo da consolidação da produção em ciências sociais nas décadas anteriores. Em linhas gerais eram estes os principais argumentos de um texto que apresentei em um GT da Associação Nacional de Pesquisadores em Ciências Sociais, em 2002, jamais publicado senão nos anais daquele evento, justamente porque o essencial seria incorporado à tese, na qual substituí o qualificativo "profissional" por "espetáculo" como uma das variantes possíveis em torno da qual poderia ser agrupada parte da diversidade dos futebóis.

\footnotetext{
${ }^{5}$ VELHO. Gilberto Freyre e o futebol-arte, 2004, p. 233-8.

${ }^{6}$ O livro, reimpresso em 2003, era de difícil acesso na década de 1990 e quando eu o obtive havia outras urgências em relação à escrita da dissertação. Assim que o trabalho ficou pronto e antes que a banca fosse realizada, li ansiosamente o livro, porque estava certo que seria inquerido a respeito. Isto não aconteceu e, para minha surpresa depois de concluída a leitura, o livro não era essencial à dissertação, o que me fez pensar que a história do torcer e do jogar, em que pese os vínculos óbvios, deveriam ter vida própria.
} 
O uso da noção de futebóis foi, portanto, uma estratégia para afirmar a diversidade e ao mesmo tempo demarcar a diferença entre a discursividade midiática e a nossa. Que o mainstream não reconheça senão o futebol de espetáculo, e se envolva em debates acerca do seu destino, é perfeitamente compreensível e aceitável. Dialogar com esta produção discursiva, da qual estamos próximos, obviamente, é algo diverso do que segui-la, razão pela qual as ciências sociais - ou os estudos esportivos, como argumentarei na sequência - precisam criar sua própria agenda.

\section{AS INFLUÊNCIAS PONTUAIS}

Embora até aqui tenha utilizado minha experiência de pesquisa para contextualizar a produção das décadas de 1980 e 1990 e seus impasses, gostaria de reiterar como esta produção é, em boa medida, o resultado de um projeto coletivo não intencional, de intenso diálogo entre as produções que foram se acumulando lentamente no período. Toledo (1996) que já havia influenciado minha dissertação de mestrado, acabara de transformar sua tese em livro quando eu estava trabalhando na minha, razão pela qual pude incorporar e adequar algumas de suas ideias. Na "Introdução" de Lógicas no futebol, Toledo ocupara-se da justificação e articulação das três partes da sua etnografia, a saber: sobre torcedores, profissionais e especialistas (mídias). ${ }^{7}$ Neste caso, o termo "profissional" adquiria um sentido estrito, referindo-se a um segmento de agentes envolvidos diretamente com a consecução do espetáculo, com rotinas, competências e remunerações afins. Tratava-se, pois, de um uso já distante do par dicotômico, mas a proposição de Toledo suscitava outros desdobramentos.

Sob certo aspecto, a tripartição sugerida parecia ser apenas uma forma de apresentar o texto, fortemente marcado pela abordagem etnográfica - ao menos em relação aos profissionais e aos torcedores. Esta hipótese seria plausível dada a ausência de uma arguição ostensiva que justificasse a tripartição ou a adoção de um dos conceitos utilizados, ao que parece com significados muito próximos: "três

\footnotetext{
${ }^{7}$ TOLEDO. Lógicas no futebol, p. 15-27.
} 
realidades dentro do campo esportivo" (p. 15); "conformação triádica" (p. 16); “'situações rituais' estabelecidas por um princípio classificatório simbólico com base [...] [n]a organização social (p. 16); “configuração ternária” (p. 18) "alguns níveis e sentidos" (p. 27) [grifos meus]. Sob um outro olhar, a "Introdução" sugeria que esses universos possuíam certas especificidades, embora não fosse de interesse de Toledo precisar as fronteiras, razão pela qual a nomeação do seu princípio classificatório alternava-se. As fronteiras a que me refiro não seriam apenas entre os segmentos futebolísticos - torcedores, profissionais e cronistas - mas também teóricas, flertando com aportes de diferentes matizes.

Havia outras possibilidades de interpretar a hesitação. Qualquer que tivesse sido a razão da alternância de termos, eles suscitavam um trânsito entre o empírico e o teórico, evidenciado pela referência à "organização social” e, supostamente, a um "princípio classificatório" que estaria a orientá-la ou, preferindo-se, "situações rituais" geradas a partir de tal organização. Outro aspecto a se destacar diz respeito à relação de complementariedade entre uma dimensão mais "sociológica", atestada pela presença de termos como "campo" e "configuração", de um lado, e outra mais "antropológica”, notada pela referência a noções como as de "princípio classificatório simbólico" e "níveis de sentido". Talvez tenha feito uma interpretação idiossincrática, lendo as referências às noções de "campo" e de "configuração" como uma influência não declarada de Bourdieu e Elias, e na esteira dessa constatação imaginado que Toledo estivesse, de algum modo, sugerindo a impossibilidade de abordar o futebol sem algum recurso demarcatório, do contrário o livro não teria razões para se chamar Lógicas no futebol. Em outros termos, era como se a produção estivesse avançando e já não fosse possível um tipo de abordagem totalizante como aquela que havia notabilizado as primeiras incursões sobre o futebol - ou que ainda pode ser notada entre aqueles que se aventuram pela primeira vez na área - em que não se faz distinção entre torcer, jogar, gerir, mediar e assim por diante. 
Voltarei à sugestão de Toledo em seguida, pois antes preciso resgatar outra influência decisiva: a noção de "mundos", de Howard Becker. 8 Tive contato com o livro de Becker ${ }^{9}$ em estágio já avançado da pesquisa sobre a formação de jogadores, na ocasião em que havia me interessado em trabalhos do campo da sociologia/antropologia da arte. Como havia declinado do uso do adjetivo "profissional" para designar aquela dentre as "três realidades" com as quais a formação de jogadores possuía maior proximidade, e em seu lugar passara a usar o termo "espetáculo", encontrava-me em busca de subsídios teóricos, escassos no espectro da literatura esportiva para abordar esta questão. ${ }^{10}$ Apesar do interesse pelo livro de Becker, relutei em adotar a noção de "mundos", pela proximidade e risco de haver confusão a de "universo", consagrada pela coletânea de DaMatta (1982). De outra parte, havia a sugestão de Toledo, que poderia ser seguida, talvez aprofundada, e o caminho indicava que isto seria possível com ferramentas que circunscrevessem melhor os fatos e os eventos futebolísticos que estavam sendo etnografados. ${ }^{11}$

\footnotetext{
${ }^{8}$ Quem leu meu livro ou mesmo a tese poderá estranhar esta recuperação, porque embora exista referência à noção de "mundo das artes" (Damo, 2005, p. 29) e Becker conste nas referências bibliográficas da tese, não há qualquer conexão entre elas - pelas regras da ABNT, Becker sequer deveria constar nas referências! Foi mais que uma omissão; foi uma injustiça, se considerada a influência exercida pela leitura do livro Os mundos da Arte, em contraste com a ausência de referências explícitas, sequer uma nota, na tese.

${ }^{9}$ A publicação original é de 1982 e eu tive acesso à versão francesa, de 1988. Há uma tradução realizada em Portugal (BECKER, 2010), bem posterior à escrita da tese e ainda pouco conhecida no Brasil se comparada a outras publicações deste autor.

10 "Escasso" talvez não seja o termo mais apropriado, porque há referências dispersas em toda a parte. No entanto, elas podem ser agrupadas em dois registros, basicamente. Um deles genérico, para adjetivar performances destacadas. Outro, mais circunscrito, é inspirado nas ideias de Guy Debord (1992), veiculadas em seu célebre manifesto "A sociedade do espetáculo". As influências de Debord foram adaptadas ao esporte por Jean-Marie Brohm e seus discípulos, articulados em torno da revista Quel Corps?. Trata-se de um uso crítico, por vezes excessivo, cujo objetivo é desqualificar o esporte por seus vínculos ideológicos com o dinheiro, o disciplinamento dos corpos e as ideologias reacionárias - hipóteses pertinentes, embora reducionistas quando aplicadas ostensivamente. Afora isso, temos as contribuições de Hans Gumbrecht, em relação às quais tenho certas ressalvas (Damo, 2015), mas que podem ser um bom ponto de partida. Minha posição, não dogmática, é de que a estética é uma chave central para entender o esporte, mas é preciso considerar que o espetáculo está tanto na performance atlética - e em todas elas, não exclusivamente naquelas observadas nos estádios - quanto na forma como ele é apreciado, sendo que entre eles existem múltiplas mediações. Estética implica mais que "beleza/torpeza"; implica emoção, engajamento e imaginação, tanto em seus aspectos físicos quanto psíquicos e sociais.

${ }^{11}$ Como escrevi na ocasião, tinha pequenas ressalvas com a sugestão de Toledo: na "Introdução" não era mencionado o fato de serem "as três realidades" circunscritas ao universo "profissional", mas havia muita "realidade" que não estava contemplada neste recorte; sugeri uma quarta "realidade", para tratar dos dirigentes - em Toledo eles são incluídos entre os "profissionais" - um universo com agências, agentes, agendas e tensões específicas.
} 
Circunscrever, em meu caso, implicava conectar algo concreto - uma prática corporal específica - com um determinado espectro simbólico - o que significa praticar futebol profissionalmente? Olhando em perspectiva, Becker teria sido útil se tivesse desejado seguir o futebol a partir da lógica das práticas, e teria dado um excelente trabalho. Mas este projeto, que chegou a ser cogitado e, de certa maneira foi contemplado, ainda que sem o devido tratamento teórico, acabou se desdobrando naquele que acabaria sendo inscrito na tese, de seguir os praticantes profissionais, o que implicou no afastamento progressivo de outros praticantes e, simultaneamente, na aproximação com agentes ou "mundos" tais como o do trabalho, do dinheiro, do dom, do espetáculo, da alta performance, da celebração e dos rituais. A diversidade dos "mundos do futebol" seria o ponto de partida, não o de chegada, e isso explica, em parte, a adoção de um protótipo classificatório mais ortodoxo daquele de Toledo - mas justifica a omissão a Becker.

De um ponto de vista teórico, portanto, a noção de futebóis foi influenciada pela ideia de diversidade, que é tipicamente antropológica, mas foi de Becker - um sociólogo - o livro usado para abanar as cinzas desse braseiro. A abordagem de Becker, sabidamente informada por um viés interacionista, não era um modelo a ser seguido sem mediações. Na verdade, seu viés pluralista colidia com uma tendência, ilustrada pela "Introdução" de Toledo, de identificar arranjos em torno de narrativas específicas e de buscar certa verticalização das temáticas. Havia um aparente paradoxo entre estas duas abordagens, embora não fosse difícil equacioná-lo, tendo em vista outros modelos bem-sucedidos, como a etnografia de Christian Bromberger (1995). Embora Le Match de Football seja uma investigação generalista, como fora característica da década de 1980 e 90, a etnografia focada nos torcedores lhe proporcionou um direcionamento analítico. A etnografia de Bromberger é uma investigação sobre o jogo, em si, antes de seu entorno, de tal modo que o livro, se fosse para ser preciso em relação ao objeto, deveria se chamar "La passion partisane" - como consta no seu complemento - e não Le Match... - o título principal. A minha etnografia de então estava focada no jogar e, particularmente, no aprendizado das competências para jogar profissionalmente, 
razão pela qual tudo o mais atinente ao mundo dos futebóis deveria compor o pano de fundo ou ser ignorado. ${ }^{12}$

Se o objetivo da tese fosse propor um modelo teórico para pensar a pluralidade do futebol provavelmente teria sido um fracasso. Por sorte ou outra razão qualquer, fui poupado de críticas mais contundentes, a começar pelo termo "matriz", usado para modular cada qual das quatro possibilidades sugeridas para reagrupar a diversidade dos futebóis: "espetacularizada", "comunitária", "bricolada" e "escolar".13 Para piorar, fiz menção a um suposto "átomo futebolístico", inspirado abertamente em Lévi-Strauss, um tipo de analogia que, olhando em retrospectiva, parece desnecessário ou mesmo descabido, pois o objetivo não era partir para uma análise estruturalista das práticas esportivas. Isso poderia até ser cogitado, mas não era o momento e se fosse o propósito haveria de ter realizado um investimento mais denso do ponto de vista teórico. Sem uma defesa contundente, o uso do termo matriz deixou a impressão de ser uma classificação ortodoxa, quando o objetivo era explicitar o fato de que minha tese tratava do futebol de espetáculo, e o faria a partir da formação de jogadores, o que pressupunha um atravessamento progressivo das outras práticas até um deslocamento ou circunspecção ao circuito profissional e os dispositivos atinentes.

A noção de matriz deu mais a ideia de um sistema do que de processo ou de fluxo. Tivesse a oportunidade de reescrever a proposta, provavelmente substituiria "matriz" por "circuito", inspirado na utilização deste termo por Viviana Zelizer (2005) ao tratar da diversidade de mercados no espectro do capitalismo, porque o termo sugere uma ideia de fluxo - no caso da formação de jogadores poderia ser pensado como um fluxo de praticantes, de técnicas corporais, de modos de governo, de dinheiro, afetos e assim por diante. A noção de Zelizer ajudaria a pensar que as práticas atinentes à formação e atuação profissionais fazem parte de um circuito específico, uma espécie de mainstream, vistas como legítimas do ponto de vista da estética e da eficácia. Logo, são as práticas tidas como exemplares,

\footnotetext{
${ }^{12} \mathrm{Na}$ tese há pelo menos um capítulo "bastardo", considerado desnecessário pela banca, inclusive, embora tenha sido escrito com muito zelo, após um meticuloso trabalho de campo. $O$ capítulo em questão não compõe o livro originado da tese, tendo sido publicado 15 anos depois, numa versão ligeiramente adaptada (DAMO, 2017).

${ }^{13}$ DAMO. Do dom à profissão, 2007, p. 33-49.
} 
cultuadas nos outros circuitos, que procuram imitá-las, embora restritas a segmento elitizado de praticantes.

Faria outros ajustes, agregando um quinto circuito, o futebol de mulheres, aos outros quatro. Não é só a questão de gênero que merece destaque e tampouco são as regras ou as técnicas corporais que exigem um tratamento específico para o futebol de mulheres. ${ }^{14}$ Este futebol tem uma história singular; sua diáspora foi bloqueada e, de certo modo, ela pouco tem a ver com questões de ordem geográfica. Também não é um circuito exclusivo de mulheres, porque embora estas sejam as praticantes, boa parte dos times/clubes e competições é dirigida por homens - ainda é; talvez isso mude rapidamente. Há muitos embates em termos de políticas de corpo e de gênero associadas a este circuito e a maneira como eles são enfrentados serve para repensar a história social do futebol dos homens, algo um tanto naturalizado pelo fato de que são homens quem têm escrito esta narrativa.

E porque não um sexto circuito, para tratar do "futebol adaptado", praticado por pessoas com deficiência? E um sétimo, para tratar dos futebóis "dissonantes", na esteira da proposição de Wagner Camargo (2016). E o futebol dos indígenas, haveria de ser tratado como um circuito particular? Se isto parece razoável, então poderíamos pensar num oitavo circuito ou numa quantidade indefinida, pois a ideia, agora mais amadurecida, não sugere um confinamento da diversidade em um número limitado de categorias, mas de agrupamentos não ortodoxos que permitam, de um lado, apreender a diversidade, e de outro evitar a generalidade, forjando-se conexões teóricas apropriadas aos e entre os diferentes circuitos.

A defesa da horizontalidade epistemológica dos futebóis poderia soar demagógica para as circunstâncias nas quais fora anunciada - uma tese sobre o futebol de espetáculo. E o fato dela não ter sido explicitada com a ênfase devida poderia ter relegado o propósito ao ostracismo ou suscitar uma crítica severa. Não foi isso o que aconteceu, embora seja pretensão em excesso supor que as diversas teses sobre o futebol de várzea levadas a cabo à posteriori, por exemplo, sejam um desdobramento da apregoada horizontalidade. ${ }^{15}$ Seria mais correto supor que, cedo ou tarde e independente da autoria, haveria de ser feita uma crítica à

\footnotetext{
${ }^{14}$ KESLLER, 2015.

${ }^{15}$ PIMENTA, 2009; MISKIW, 2012; SPAGGIARI, 2014.
} 
centralidade ocupada pelo futebol de espetáculo - ou, mais precisamente, ao "profissional" em detrimento "dos amadores" - afinal é uma característica marcante das ciências sociais tensionar o status quo.

\section{INFLEXÃO PASSAGEIRA OU CRISE?}

Mais do que rememorar as condições de emergência da noção de futebóis, gostaria de sugerir que estamos em outro contexto de se pensar a diversidade. Esta constatação é pertinente em relação à produção no campo dos estudos esportivos, mais atento à polifonia das práticas, e também ao futebol de espetáculo no Brasil, sujeito a um processo de "modernização elitizada" cujo ápice foi a arenização dos estádios. São duas proposições com largas implicações e o fato de enunciá-las de modo tão breve deve-se à percepção de que são amplamente partilhadas entre os pares. ${ }^{16}$ Para o que venho afirmando, e sobretudo para o que segue, as referências tem um recorte nacional tanto em relação à produção acadêmica quanto ao fenômeno empírico.

Em que pese nossas investigações ainda careçam de alcance internacional,17 constituiu-se no Brasil um espaço que poderia ser nominado, da forma mais abrangente, como um campo multidisciplinar de estudos sobre o fenômeno esportivo - por economia de linguagem, "estudos esportivos" - sob certos aspectos à maneira dos "estudos culturais". No interior desse espaço, o futebol ainda é hegemônico, se observarmos a produção numa temporalidade estendida, mas não tanto quanto nos primórdios (anos de 1980 e 1990). É interesse notar como tal espaço foi sendo constituído por trânsitos disciplinares - e aqui os grupos de

\footnotetext{
${ }^{16}$ Em relação à "arenização" e seus efeitos não tenho dúvidas de que esta é uma posição amplamente partilhada pelos pares. Quanto à produção acadêmica, apesar de alguns trabalhos focando o "estado da arte" (GIGLIO; SPAGGIARI, 2010), não há críticas mais vigorosas a respeito. Tenho manifestado certos pontos de vista em relação à produção das décadas de 1980 e 1990 e suas influências damattianas em textos já publicados (DAMO, 2014; 2016; 2017b), mas sendo integrante da configuração analisada há limitações óbvias nessas incursões.

${ }^{17}$ Por óbvio, não estamos isolados e uma parte expressiva das nossas influências teóricas vem do exterior - Elias, Bourdieu, Hobsbawm para as gerações mais antigas; Buttler e Haraway para os contemporâneos - nem ignoro o trânsito internacional de pesquisadores brasileiros ou a presença de estrangeiros em nossos eventos - notadamente de argentinos. No entanto, destacase, em nossos trabalhos, um intenso diálogo entre autores nacionais, e isto não precisa ser interpretado como algo negativo, antes como um indicativo de que a produção é qualificada.
} 
pesquisa, eventos e publicações contribuíram decisivamente - embora isto não tenha sido um movimento planejado, tampouco influenciado por um teórico, grupo ou outra tradição nacional, nem mesmo pelo mantra "trans", "inter" ou "multi" disciplinar. Não arriscaria nem mesmo afirmar que a multidisciplinariedade seja uma virtude, muito menos desejada; ela simplesmente existe, é uma constatação.

Talvez seja prematuro afirmar de modo peremptório que o interesse por estudos no espectro do futebol de espetáculo esteja declinando ou de que há uma crise, porém há indícios. É preciso considerar as transformações aceleradas pelas quais passou o nosso futebol de espetáculo nas últimas décadas para notar como isto pode - ao menos deveria - ter impactado as investigações. Em diversos textos recentes tenho reiterado, às vezes de forma monótona, que a interpretação damattiana precisa vir a ser suplantada. Isto não significa retirar os créditos de DaMatta, nem recuar em relação à importância daquelas ideias embrionárias para o desenvolvimento de um campo de estudos no Brasil. Já apontei as principais razões pelas quais a interpretação de DaMatta foi tão convincente. Não teria como reproduzi-las, mas não gostaria, de modo algum, que a riqueza e mesmo a complexidade daquele texto aparentemente simples fosse reduzida ao rótulo de romântica, que sou forçado a empregar aqui. Romântica porque afinada com a matriz freyriana de pensar a formação social do Brasil, vinda à tona num contexto político nacional de intensa mobilização popular contra a Ditadura e afinada com a emergente antropologia urbana brasileira, comprometida com o "ponto de vista dos nativos". ${ }^{18}$

Os escritos de DaMatta sobre futebol são ensaísticos, sem um trabalho de pesquisa empírico, quanto menos etnográfico. Como nativo da sociedade que descreve, usa a sua experiência cotidiana como suporte, com a cidade do Rio de Janeiro e o Maracanã, de seus memoráveis jogos e públicos das décadas de 1950 a 1980, como sendo o "campo" de uma etnografia imaginada. Desejando, poder-se-ia seguir com este exercício hipotético e não seria difícil de se chegar à geral do Maracanã, área reservada ao povo naquele que fora construído para ser um cenário metonímico da nação. ${ }^{19}$ Passadas algumas décadas desde o texto original

\footnotetext{
${ }_{18}^{18}$ DAMO. Romantismo e futebol nas ciências humanas brasileiras, p. 9-29.

19 HOLLANDA. O fim do estádio-nação? Notas sobre a construção e remodelagem do Maracanã para a Copa de 2014, 2014, p. 321-348,
} 
de DaMatta, não apenas a geral do Maracanã foi extirpada depois de sucessivas reformas, senão que a última onda de atualização dos estádios repaginou todos os espaços e aqueles destinados ao povo foram extintos ou drasticamente reduzidos. As novas arenas perderam, por isso, parte vital das qualificações que tornaram os estádios de outrora tão apreciados para se realizar observações de campo. ${ }^{20}$ Os grupos populares, nossa razão principal para investigar o futebol ou a justificativa para "estar lá" de um jeito outro que não apenas como torcedores, foram sendo gradativamente excluídos com a arenização. Definitivamente, o futebol de espetáculo mudou, e também por isso o texto de DaMatta tornou-se anacrônico.

Justo no momento em que as ciências sociais tornaram-se mais permeáveis aos estudos futebolísticos, deparamo-nos com um cenário empírico pouco alvissareiro, como se nosso objeto tivesse desaparecido. A realização da Copa 2014 no Brasil foi um ponto de inflexão importante, porque escancarou certos limites da nossa produção, inclusive no que concerne às manifestações torcedoras. Se a noção de futebóis tem alguma utilidade, então é preciso estendê-la a todas as práticas, incluindo-se as torcedoras. É fato que nossa produção não ignorou a diversidade das formas de torcer, mas o fez tendo no público vinculado às classes populares e nas suas manifestações, estéticas e políticas, nas quais se destacam as performances das TOs, espécie de representação idealizada dos torcedores e do torcer. Outros perfis, que agora adquiriram maior notoriedade, foram ignorados pela nossa bibliografia, como se estivessem ausentes dos estádios. E dessa gente não se pode falar como DaMatta, de que estejam ali para experienciar uma lição de democracia, de modo que este futebol - as arenas com seu público elitizado - já não nos parece digno das ciências sociais. Parece nos faltar agora um equivalente para o discurso do "ópio do povo", mas voltar ao passado não é uma boa opção.

De maneira geral, tenho a impressão de ter havido um refluxo da temática. Há menos jovens estudantes de ciências sociais ou de disciplinas afins

\footnotetext{
${ }^{20} \mathrm{Em}$ um texto em preparação sobre esta questão, deverei apresentar argumentos mais detalhados que, em parte, matizam esta afirmação. De fato, as novas arenas expulsaram o público das classes populares, mas seria equivocado afirmar que antes das reformas os estádios fossem espaços amplamente democráticos. A sub-representação das mulheres e a hostilização de todos os tipos que não performam um dado padrão de virilidade heteronormativa (BANDEIRA, 2016) estão longe de fazer dos velhos estádios um espaço polifônico, como por vezes ele é reivindicado em textos que criticam as arenas.
} 
entusiasmados com a diversidade e a polissemia dos estádios, e não sem razão. Até o encantamento com as TOs parece haver declinado, em parte porque não logramos renovar teoricamente as abordagens, em parte porque tais grupos seguem, no essencial, a rotina de três décadas - faccionalismo, performances masculinas, alianças clientelistas com dirigentes de clubes, etc. Mas há também outros movimentos interessantes que podem ser notados. Um deles é de crítica ao futebol de espetáculo - nos termos êmicos, "ao futebol moderno" - uma modalidade de abordagem que havia declinado desde a contestação do "ópio do povo". ${ }^{21}$ Trata-se de uma narrativa descolada daquela inaugurada pelos neofrankfurtianos, ainda que por vezes se possa identificar nela certos traços androcêntricos e saudosistas, imputando ao futebol do passado um viés inclusivo que talvez ele não tivesse - em termos de gênero, por exemplo. Outro movimento, talvez o menos pronunciado ou menos visível até o presente, consiste em permanecer trabalhando com os mesmos temas e os mesmos espaços, mas com abordagens teóricas distintas. Estes dois primeiros movimentos são protagonizados, basicamente, por pesquisadores que já estão há algum tempo envolvidos com a temática do futebol e por outros, mais jovens, que tiveram um contato mais prolongado com a literatura "canônica".

Há, no entanto, dois outros movimentos que despertam interesse. Um deles, já com produções significativas, vinculado ao futebol de mulheres. Nem todas as pesquisadoras são mulheres, embora elas predominem - como mostrarei em seguida - e isto, por si só, já é um bom indicativo de mudanças, além do fato desta produção ter se estabelecido em paralelo à produção sobre o futebol dos homens, sobretudo do ponto de vista das influências teóricas. Essas pesquisas trazem um aporte teórico do campo dos estudos de gênero, sobretudo, e tem oxigenado a compreensão dos fenômenos futebolísticos no seu conjunto. Um outro grupo, que está chegando ao campo, é caracterizado por jovens envolvidos com militância política entre grupos organizados. São grupos ainda em fase de consolidação, implicados com o clubismo e a experimentação das emoções estéticas características desse meio, mas igualmente preocupados em combater as diferentes faces do

\footnotetext{
${ }^{21}$ LOPES; HOLLANDA. "Ódio eterno ao futebol moderno": poder, dominação e resistência nas arquibancadas dos estádios da cidade de São Paulo, 2018, p. 206-232.
} 
sexismo e da xenofobia. Ainda é prematuro tecer considerações acerca do resultado desta dupla inserção e de como tal experiência vai ser vertida em termos epistemológicos, embora haja fortes indicativos de que a renovação será positiva.

No conjunto, há claramente uma dispersão temática. Superamos a agenda marcada pela questão da identidade nacional, dos estilos de jogo, do fluxo de profissionais e outros assuntos dos quais nos ocupamos até o presente. Não precisamos abandonar tais problemáticas, mas abrir-se a novas perspectivas é essencial a qualquer projeto científico, cujos avanços se dão em razão da crítica. Não deixa de ser curioso notar como a noção de futebóis, que se estabeleceu lentamente, venha sendo invocada de modo mais frequente e contundente nos últimos tempos. Se na origem fora um conceito empregado, basicamente, num sentido epistemológico, agora é o momento de pensá-lo também num registro político. E isto talvez já esteja acontecendo.

\section{NóS, OS OUTROS DOS FUTEBóIS}

Se fosse o caso de seguir com sugestões de ampliação dos circuitos futebolísticos, deveríamos nos incluir em um deles, o dos intelectuais, que praticam o futebol com as palavras. Contudo, não somos insiders como os mediadores especializados, umbilicalmente vinculados ao futebol de espetáculo. Todavia, para não transformar os circuitos futebolísticos em anéis dantescos, é suficiente considerar o fato de que integramos um campo discursivo próprio. Ainda assim, temos nossos eventos ou jogos - bancas, GTs, seminários, etc - e se a analogia procede, nossa copa do mundo seria o Simpósio Internacional de Estudos sobre Futebol (SIESF), sediado no Museu do Futebol, ${ }^{22}$ com periodicidade quadrianual, coincidindo com as Copas FIFA de futebol masculino - foram três edições até o presente, a partir de $2010 .^{23}$

\footnotetext{
${ }^{22}$ O Museu do Futebol foi inaugurado em 2008, com uma proposta atualizada em relação à museologia contemporânea, de modo que além de exibir um acervo variado sobre a prática dos futebóis tem proporcionado aos seus visitantes a possibilidade de interação e, para os fins que aqui importam, acolhido e incentivado exposições e debates que narram e tensionam a história dessas práticas.

${ }^{23}$ No mesmo patamar está o "Simpósio Internacional Futebol, Linguagem, Artes, Cultura e Lazer", com três edições realizadas até o presente (2014, 2016 e 2018), organizado pelo Grupo
} 
Uma olhadela nos temas abordados e nos trabalhos apresentados nos SIESFs contribui para consolidar o argumento de que está havendo mudanças na produção. ${ }^{24} 0$ primeiro SIESF, realizado em maio de 2010, num clima de euforia em razão da anunciada realização dos megaeventos esportivos no Brasil - A Copa 2014 havia sido oficializada em 2007 e os Jogos Olímpicos em 2009 - e da profusão de recursos para a pesquisa por parte das agências estatais - federais, sobretudo, e algumas estaduais - teve o seguinte tema: "Futebol, Sociedade e Cultura: Pesquisas e Perspectivas". Sem entrar em detalhes sobre os meandros dos debates - e sem que isso pareça uma crítica - diria que o título amplo e genérico retrata bem um certo acúmulo produzido até então, cuja ênfase fora centrada no binômio cultura e sociedade. Como confirma um resumo "oficial" realizado à posteriori, ${ }^{25}$ "o evento discutiu o papel e a importância desse esporte na sociedade brasileira a partir de estudos e pesquisas inéditas".

O segundo simpósio, em maio de 2014, às vésperas da Copa do Mundo, foi realizado numa atmosfera distinta, impregnada pelas surpreendentes Jornadas de Junho de 2013. O fato das mobilizações terem sido iniciadas com uma pauta voltada ao transporte público - como é rotina quase todos os anos - e terem adquirido proporções gigantescas justo durante a realização da Copa das Confederações, confirmava o argumento renitente acerca da importância do futebol no Brasil e de seus vínculos com a construção da nação. De outra parte, havia inquietude acerca do que poderia ocorrer com os enfrentamentos prometidos por alguns grupos políticos - à esquerda do PT, incluindo-se os anarquistas - durante a Copa e, sobretudo, dos efeitos em relação às eleições presidenciais que ocorreriam no mesmo ano, uma vez que as mobilizações haviam

de Estudos sobre Futebol e Torcidas (GEFuT) - um dos mais longevos e atuantes no Brasil em parceria com o Núcleo de Estudos sobre Futebol, Linguagem e Artes (FULIA). O primeiro grupo é vinculado à Escola de Educação Física e o segundo à Faculdade de Letras, ambos da UFMG. Em função do acesso facilitado aos anais dos eventos e por cobrir uma temporalidade maior, vou utilizar os simpósios vinculados ao Museu do Futebol como referência para ilustrar algumas das hipóteses que seguem.

${ }^{24}$ As chamadas dos eventos, bem como os artigos que compõe os anais, encontram-se disponíveis em: http://www.simposiofutebol.museudofutebol.org.br/.

${ }_{25}$ Infelizmente não arquivei 0 material de divulgação dos dois primeiros SIESFs e não consegui acesso digital à chamada do primeiro evento, apenas uma síntese sobre ele na divulgação do segundo. 
desgastado a popularidade dos políticos em geral e da então presidenta Dilma Rousseff em particular. ${ }^{26}$

Havia uma espécie de frustração pela tibieza das críticas que havíamos realizado em relação ao alinhamento de um governo que se propunha progressista - e de fato o era em muitos aspectos - à ladainha marqueteira das grandes agências esportivas e seus dirigentes corruptos. Olhando pelo retrovisor, a impressão em 2014 é de que em 2010 estávamos, em alguma medida, mistificados pelo próprio objeto, razão pela qual o rótulo de românticos teria sido ameno. Em contrapartida, as críticas em relação à parceria do governo federal com a FIFA já tinham seus eixos programáticos e seus protagonistas estabelecidos. 0 melhor, para eles, era que a Copa fosse um "fiasco", para macular de vez a imagem do governo petista. Nosso grupo não tem compromissos com o petismo ou com qualquer outro partido, mas de forma geral temos ideais progressistas. Atacar o governo às vésperas da Copa seria pegar carona nas críticas da mídia esportiva e de vários segmentos conservadores, ainda que não pudéssemos ignorar a pertinência delas - ou de parte delas, ao menos - e o fato de que o protagonismo não era nosso. Em linhas gerais, nossas críticas estavam dirigidas à elitização dos estádios, e neste aspecto os efeitos foram praticamente nulos. 0 que mobilizou os manifestantes foi a questão do financiamento público, e sobre isto nossa bibliografia não dizia mais do que os slogans que estavam nas ruas - algo contundente, porém genérico, apropriado para eventos performáticos, mas irrelevante para o debate acadêmico.

De qualquer sorte, o II Simpósio captou a necessidade de uma autocrítica, pelo que se pode depreender da categoria "resistência" em meio ao título: “Expressões, Memórias, Resistências e Rivalidades". Em que pese um viés fortemente culturalista e identitarista, - o objetivo do segundo simpósio seria discutir as "práticas futebolísticas e suas significações culturais, questionando o seu papel como indicador de repertórios de identidade" - havia a explicitação de que ao menos esta última questão estava inserida num "universo assinalado por

${ }^{26} \mathrm{Em} 2013$ um dos slogans mais populares questionava quem seriam os beneficiados com a Copa - "Copa para quem?". Já em 2014 os mesmos grupos apresentaram-se com uma proposição mais radical - "Não vai ter Copa!" - mas a adesão popular foi pequena e a vigilância foi redobrada, de modo que o movimento se dissipou. 
disputas políticas e simbólicas". De fato, não havia como ignorar as disputas em torno da ideia de nação tendo as manifestações de 2013 popularizado slogans como "Da Copa eu abro mão, mais saúde e educação" e "Queremos escolas e hospitais 'padrão FIFA'”.

Se em 2010 nenhum dos trabalhos apresentados nos GTs continha o termo "política" no título, quatro anos mais tarde haveriam seis (entre 134), mas o termo resistência, em que pese a chamada do evento, só constou em um título, sobre o movimento punk e anarquista na várzea paulistana - Faria, 2014. Já em 2018, a guinada política seria explícita, a começar pela chamada do evento: "Políticas, Diversidades e Intolerâncias". Ao menos sete trabalhos (entre os 157 pesquisados) continham o termo "política" no título, outros cinco se reportavam a "poder" (em 2010 haviam sido dois e em 2014 nenhum) e quatro usavam a palavra "resistência" (havia uma referência do tipo em cada qual dos eventos anteriores).

$\mathrm{Na}$ chamada do II Simpósio constava que o primeiro havia permitido realizar um "balanço da produção" e que o objetivo agora seria "ampliar o alcance dos debates, promovendo o intercâmbio entre a produção nacional e estrangeira sobre futebol”. Já na chamada do evento de 2018, sugeria-se não apenas um balanço, mas um "balanço crítico". A palavra "crítica", completamente ausente nas duas primeiras chamadas, aparecia duas vezes no resumo do III Simpósio: a primeira para qualificar o viés do "balanço" e a segunda para sugerir um "aprofundamento da percepção crítica sobre os dilemas e contradições da realidade atual do futebol". 0 texto não é explícito em relação a quais "dilemas" os participantes deveriam se debruçar, mas certamente não eram "os nacionais", como apontava a bibliografia das décadas anteriores. Quanto às contradições, há indicativos de que elas eram tidas como decorrentes da elitização catapultada pela Copa 2014 e pelas intolerâncias observadas num contexto que se supunha democrático. A propósito, em 2018, já não havia mais referências explícitas à Copa - embora tenha havido, durante o evento, uma mesa e uma sessão de apresentação de trabalhos a respeito, com pequena adesão de trabalhos e de público - ante às "estruturas de poder (FIFA, COI, CBF)", devidamente nomeadas. Ao invés de reforçar a importância dos aspectos sociais e culturais do futebol, este seria agora tratado como "fenômeno complexo, dinâmico e multifacetado". 
Se os SIESFs são uma boa régua, pode-se afirmar que ocorreu uma mudança significativa de perspectiva, com um descolamento progressivo das demandas do próprio campo futebolístico - em particular do futebol de espetáculo - para uma agenda mais próxima ao universo acadêmico e às lutas políticas. Ater-se a descritores pode não ser uma boa estratégia, mas eles nos dão pistas. Assim sendo, vale ressaltar que uma das mudanças mais expressivas quanto à temática dos trabalhos apresentados ocorreu em relação à questão de gênero. Agrupando-se os descritores "mulher(es)", "feminino", "feminista” "torcedora(s)" (declinando gênero e não como adjetivo), encontram-se escassos cinco títulos no Simpósio de 2010, e apenas um a mais em 2014. Em 2018, todavia, o número salta abruptamente para 25, perfazendo aproximadamente 16\% do total de apresentações em GTs - em 2010 e 2014 haviam se mantido constantes, na faixa dos 4,5\%.

Esses trabalhos estão distribuídos, basicamente, em torno de três eixos principais: o jogar, o torcer e a mediação especializada, além de um outro segmento com temas diversos, de gestão à arbitragem. Como quase $90 \%$ das responsáveis por estes trabalhos são mulheres, tudo leva a crer que o androcentrismo temático, evidenciado nos anais dos SIESFs anteriores e na produção em seu conjunto, é resultante da hegemonia de pesquisadores homens. Com a entrada do futebol de mulheres em cena, por conta de pesquisadoras mulheres, basicamente, passou-se a declinar gênero para certos eventos e circunstâncias. Para as "Copas do Mundo", por exemplo, jamais se usou o complemento "masculina/o", razão pela qual todos os trabalhos que constam nos anais dos SIESFs citando em seus títulos as Copas - 46 entre 414 -, referem-se, na verdade, à Copa do Mundo de Futebol Masculino, e nenhum deles é sobre a competição destinada à prática das mulheres. Ainda que as mulheres tenham logrado invadir esta área até então bem marcada - salvo notórias intrusas, como Simoni Guedes e Carmen Rial, entre outras - ainda se percebe um forte viés heteronormativo. Entre os 414 trabalhos apresentados, apenas cinco fazem referência ao termo "gay" - sendo três deles à torcida Coligay - e um tem no título o termo "queer", ao passo que "homofobia", que quase todos creem ser recorrente nos estádios e em outros ambientes futebolísticos, consta em um único título ao longo das três edições dos simpósios. 
Tão ou mais preocupantes são as escassas referências à questão racial. A se considerar a produção representada nos SIESFs, não temos no Brasil qualquer problema com racismo ou, para ser fiel aos números, temos um probleminha: entre todos os títulos dos três eventos, um único tem a palavra "racismo" como destaque (DoCARMO Jr., 2010) e ainda assim referente ao caso envolvendo a acusação de Edicarlos a Maxi Lopes, em que o acusado é argentino. Ampliando-se o escopo da busca, com a inserção de "negro" e de "raça", o resultado é igualmente desolador: uma referência a "negro" no evento de 2014 e quatro no de 2018, sendo que neste último caso três são relativas a jogadores. É óbvio que, como no caso do futebol de mulheres, sub-representado até que mulheres tivessem nos sacudido da curtição em berço esplêndido, também a baixa presença de negros entre os pesquisadores da área é parte da explicação desse hiato constrangedor. Mas é parte, apenas, porque deve haver algo mais grave de errado para que depois de 40 anos tenhamos tão pouco a dizer sobre este assunto. ${ }^{27}$ Particularmente, fiquei estupefato com tamanha negligência, porque não creio que negritude seja um traço que passe desapercebido dos nossos futebóis. Então só pode ser a nossa matriz teórica, defasada a perder de vista, que está nos impedindo de ver o óbvio.

\section{ConCLUSÃo}

A Mesa de Encerramento do III SIESF, intitulada "Outros Futebóis", contou com a participação de Wagner Xavier Camargo, Aira Bonfim e Carlos Terena, e tratou de temas como o futebol dissonante - uma espécie de derivação dos esportes dissonantes -, do futebol das mulheres e do futebol dos indígenas, respectivamente. Nenhum desses futebóis havia sido contemplado naquela já superada sugestão retomada na primeira parte do texto, mas não me senti vexado por isso. A menção generosa de Aira Bonfim ao meu texto de anos atrás foi bem além do que eu haveria de esperar e merecer, e certamente não foi por conta disso que me senti tocado. Apreciando da plateia o desenrolar das intervenções,

\footnotetext{
${ }^{27}$ Há dissertações e teses sobre o tema, mas chama a atenção o fato de que essas produções não parecem terem logrado consolidar um debate a ponto de gerar pesquisas continuadas, como temos em relação à identidade, torcidas, copas e, mais recentemente, ao futebol de mulheres.
} 
primeiro dos palestrantes e depois do público, fui rememorando um percurso trilhado ao longo de mais de duas décadas, desde as incursões quase solitárias iniciadas ao longo da década de 1990, quando a bibliografia e a interlocução eram escassas, até aquele aprazível momento no qual partilhava com colegas e amigos o desfecho de um evento que, a meu juízo, mostrava o amadurecimento das nossas pesquisas e debates. Se é que se pode falar em avanço ou progresso em termos de ciências sociais, os estudos sobre futebol haviam logrado algo neste sentido. Já não estávamos a dizer o óbvio de um outro jeito, mas tentando abrir caminho para o que não é aceito como óbvio, a possibilidade de o futebol ser tratado como um fenômeno plural, efetivamente polifônico ou politécnico, em que muitos e discrepantes pontos de vista possam ser reconhecidos como legítimos.

Teria ficado o dia todo naquele auditório à escuta do nosso futebol, o dos intelectuais, jogado com as palavras. E nem era por aversão à bola, que sempre me fascinou, ou pelo gosto desmesurado pelas narrativas acadêmicas, que seguidamente me aborrecem. Estava entre colegas e amigos, repito, e de algum modo experimentava a sensação de que estávamos avançando coletivamente, de que nos movíamos na direção sublime, e quiçá ingênua, de alargar os horizontes do conhecimento. Se havia perdido um pouco do romantismo com o futebol de espetáculo, o havia reencontrado com os outros futebóis. Mas também preferia permanecer naquele acolhedor auditório, chamado Armando Nogueira, nas entranhas do Pacaembu, porque na Praça Charles Miller, em frente ao estádio, havia uma mobilização em cores verde e amarela, tendo muitas camisetas com escudos da CBF, embora na programação não constasse nenhum jogo da seleção. Aliás, havia uma ideia de nação sendo ali propagandeada, mas nada tinha a ver com a noção de futebóis, quanto menos de diversidade. Nosso esforço para esgarçar os sentidos das práticas futebolísticas e assim promover a inclusão de todas as performances no panteão do pesquisável contrastava com o que parecia ser um movimento em sentido inverso, de singularização e purificação de um ideal de coletividade. Havia muitos paradoxos no ambiente, uma sensação mista de avanços e retrocessos, de convicções e incertezas, de entusiasmo e de paralisia. 
Depois de uma intervenção de David Wood, ${ }^{28}$ perguntando sobre o nosso futuro - mesmo sendo estrangeiro, ele havia captado o clima de incertezas manifesto durante o evento - acabei fazendo uma intervenção, apontando para o palco, onde se encontravam os palestrantes que haviam acabado de falar sobre o pluralismo futebolístico e, supostamente, onde estaria "nosso futuro". Não creio que tenha me expressado claramente em relação à metáfora utilizada e se a recupero aqui não é para recompor aquela intervenção, antes para ratificar a sua pertinência. A imagem que me veio em mente - e o porquê não vem ao caso - foi um tríptico do pintor catalão Joan Miró, chamado Pintura sobre fondo blanco para la celda de un solitario, criado em 1968, nos últimos anos do franquismo.

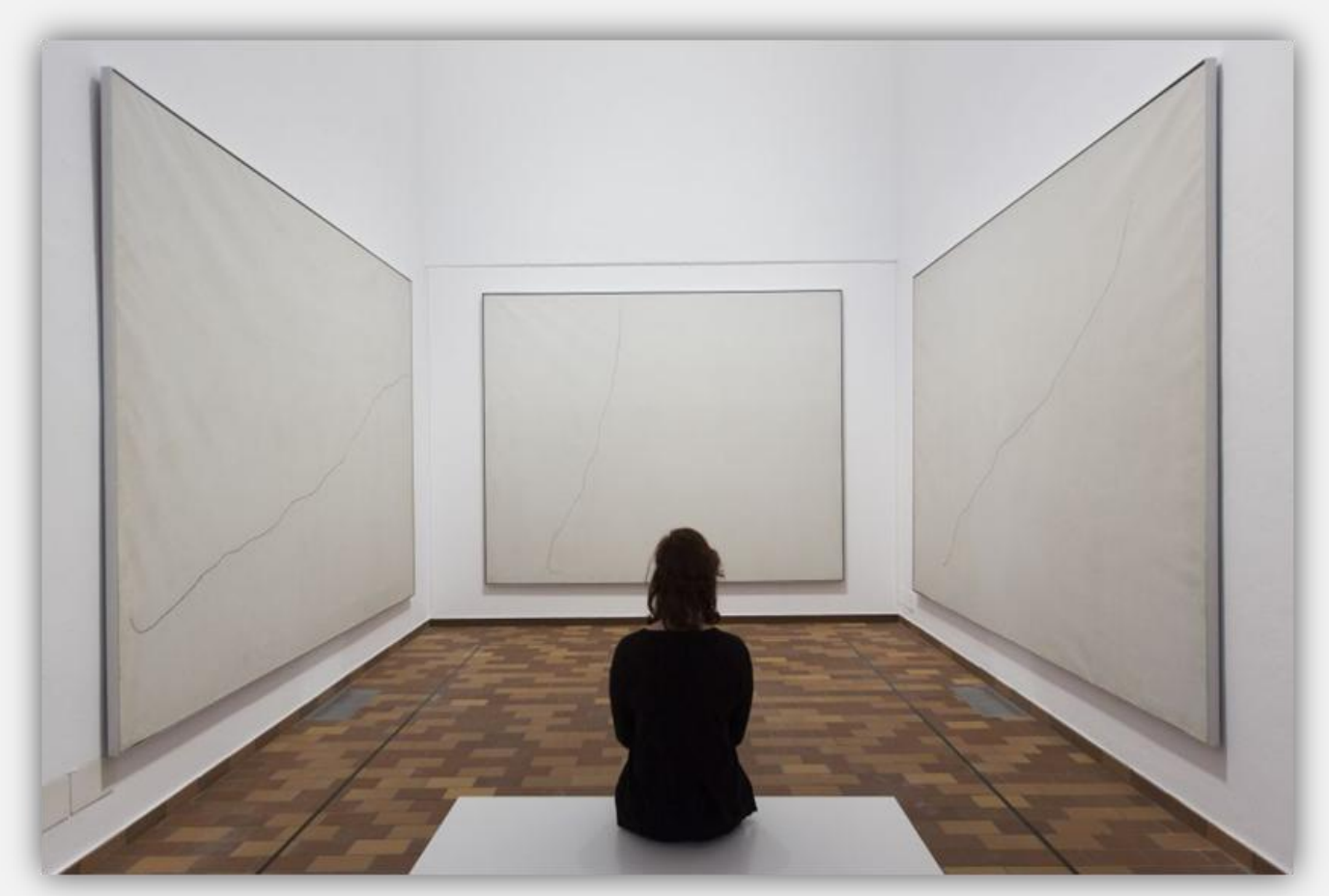

Pintura sobre fondo blanco para la celda de un solitario I, II, III Fundación Joan Miró, Parque de Montjuïc. ${ }^{29}$

${ }^{28}$ David Wood é professor na University of Sheffield e coordena, com Silvana Goellner (UFRGS/Brasil) e Verónica Moreira (UBA/Argentina), o projeto "Condições de igualdade no campo de jogo? A prática e representação do futebol de mulheres e meninas na América do Sul", tendo realizado, por ocasião desse III Simpósio, um encontro específico da rede de pesquisadores associados ao referido projeto. Faço questão de me referir ao projeto e ao encontro como indicativos de que há mudanças expressivas neste campo de produções.

${ }_{29}^{29}$ Disponível em: https://elpais.com/ccaa/2016/04/08/catalunya/1460144417_532077.html. 


\section{Como escreveu o crítico Adrian Searle,}

Los tres lienzos blancos no contienen gran cosa; no hay color, no hay formas. Cada una de las gigantescas telas muestra una única línea negra, pintada sobre un fondo irregularmente cubierto de imprimación blanca. No es difícil determinar en qué punto al fino pincel se le acaba la pintura y dónde se recarga para proseguir un camino de propósito tan incognoscible como el trayecto de una hormiga o de un ave en pleno vuelo, o el viaje del ojo a lo largo de un horizonte. 0 como ese largo cabello perdido en una sábana, recuerdo de algo o de alguien.

El solitario del que habla el título bien podría ser el propio artista, pintando una tarde con las contraventanas resguardándole del resplandor del día en su estudio de Mallorca, aquel mismo mes en el que los estudiantes se echaban a la calle en París, con el general Franco rigiendo aún los destinos de España. La idea de pintar una finísima línea cruzando una tela de tales dimensiones no deja de ser una insensatez.

¿Cómo es posible que funcione? Pues funciona. Hay una diferencia palpable entre una línea viva, tensa y, de algún modo, natural y otra que muere como una nota sorda. Al seguir el camino de la línea hacia ninguna parte sentimos la vitalidad de la línea de Miró recorriéndonos el cuerpo de la cabeza a los pies, el puño abriéndose y cerrándose en el bolsillo acusando, de alguna manera, en nuestro propio organismo la concentración del artista: la tensión en su muñeca, el movimiento de su mano. Imagino a Miró conteniendo el aliento mientras dibuja y al mirar contengo el mío también. ${ }^{30}$

Uma linha preta num quadro branco não diz muito, estou inteiramente de acordo com Adrian Searle, mas "funciona". A primeira sensação é de uma força centrípeta atuando sobre o olhar, arrastando-o para dentro do quadro, apenas para exercer, no momento seguinte, uma força em direção contrária, centrífuga, como se o mistério estivesse na imaginação de quem o contempla e não no quadro em si. Embora possa ser paradoxal, o tríptico funciona como uma abertura, porque captura a imaginação e suscita múltiplas interpretações. Um risco preto sobre um fundo branco talvez seja imaginação pura. É visceral e perturbador. Pode-se seguir em frente, ignorando-o, afinal Miró tem muitas telas multicoloridas para se apreciar, algumas delas no próprio Montjuïc, onde o tríptico está normalmente exposto. Em se deixando capturar pela obra, no entanto, sente-se um turbilhão de emoções e o máximo que se consegue fazer é apreciar, silenciosamente, até recobrar energias para sair do quadro e seguir em frente. Em si mesmo o quadro

\footnotetext{
${ }^{30}$ Disponível em: https://www.elcultural.com/revista/arte/Miro-una-fina-linea/29844.
} 
parece não ter nada a dizer; é pura imaginação de quem o aprecia, repito, como se o pintor dissesse: dane-se, se esperas que eu te entregue algo sublime.

O próprio futebol, um jogo tão simples, assemelha-se a um risco. Pelo menos é assim, na sua simplicidade, que o reivindicam muitos daqueles que são excluídos da versão espetacularizada. Em todo o caso, para transpor o fundo branco é preciso imaginação; por vezes uma atitude, que bem pode ser um drible irreverente ou então um escracho, como o de Yngrid - a personagem da epígrafe, lembram-se? Nossa produção discursiva não passa também de um risco e ainda que seja arriscado dizer, haveremos de seguir, transpondo este fundo branco - ou seria verde e amarelo? A paralisia não é uma boa opção.

\section{REFERÊNCIAS}

ANTUNES, Fátima. Futebol de fábrica em São Paulo. Dissertação (Mestrado em Sociologia), USP, São Paulo, 1992.

BANDEIRA, Gustavo. Do Olímpico à Arena: elitização, racismo e heterossexismo no currículo de masculinidade dos torcedores de estádio. Tese (Doutorado em Educação), UFRGS, Porto Alegre, 2017.

BROMBERGER, Christian. Le match de football: ethnologie d'une passion partisane à Marseille, Naples et Turim. Paris: Éditions de la Maison des sciences de l'home, 1995.

BURLAMAQUI, Luiz. A outra razão: as transformações do futebol e os seus dirigentes (1982-1995). Dissertação (Mestrado em História), UFF, Niterói, 2013.

CALDAS, Waldenyr. O pontapé inicial: memória do futebol brasileiro. São Paulo: Ibrasa, 1990.

CAMARGO, Wagner Xavier. Dilemas insurgentes no esporte: as práticas esportivas dissonantes. Revista Movimento, v. 22, p. 1337-50, 2016.

CAMARGO, Wagner Xavier; KESSLER, Cláudia Samuel. Além do masculino/feminino: gênero, sexualidade, tecnologia e performance no esporte sob perspectiva crítica. Horizontes Antropológicos, v. 23, n. 47, p. 191-225, 2017.

DAMATTA, Roberto. Universo do futebol: esporte e sociedade brasileira. Rio de Janeiro, Pinakotheke, 1982. 
DAMO, Arlei. Do dom à profissão: uma etnografia do futebol de espetáculo a partir da formação de jogadores no Brasil e na França. Tese (Doutorado em Antropologia Social) - IFCH da UFRG, Porto Alegre, 2005.

DAMO, Arlei. Do dom à profissão. São Paulo: Hucitec, 2007.

DAMO, Arlei. Del opio de los pueblos a la Antropología de lo Obvio: Lectura crítica de los escritos de Roberto DaMatta sobre futbol. Lúdicamente, n. 3. p. 1-12, 2014.

DAMO, Arlei. Futebol, engajamento e emoção. In: HELAL, Ronaldo; AMARO, Fausto. (Org.). Esporte e mídia - novas perspectivas: a influência de Hans Ulrich Gumbrecht. Rio de Janeiro: EdUERJ, p. 74-94, 2015.

DAMO, Arlei. Novas abordagens sobre o esporte em ciências humanas no Brasil. In: SPAGGIARI, Enrico; MACHADO, Jeancarlo; GIGLIO, Sérgio. (Org.). Entre Jogos e Copas - reflexões sobre uma década esportiva. São Paulo: Intermeios, p. 330-350, p. 2016.

DAMO, Arlei. Das palavras e dos palavrões - um olhar antropológico sobre formas de sociabilidade e construções narrativas nos estádios de futebol. Sociabilidades Urbanas Revista de Antropologia e Sociologia, v. 1, p. 81-100, 2017a.

DAMO, Arlei. Romantismo e futebol nas ciências humanas brasileiras. In: CORNELSEN, Elcio; CAMPOS, Priscila; SILVA, Silvio Ricardo da. Futebol, linguagem, artes, cultura e lazer (Vol II). Rio de Janeiro: Jaguatirica, p. 9-29, 2017b.

DEBORD, Guy. La société du spectacle. Paris: Gallimard, 1992.

FRANZINI, Fábio. As raízes do país do futebol: estudo sobre a relação entre o futebol e a nacionalidade brasileira (1919-1950). Dissertação (Mestrado em História) - FFLCH, USP, São Paulo, 2000.

FRANZINI, Fábio. Futebol é "coisa para macho"? Pequeno esboço para uma história das mulheres no país do futebol. Revista Brasileira de História, v. 25, n. 50, p. 315-28, 2005.

FRYDENBERG, Julio. "Prácticas y valores en el processo de popularización del fútbol, Buenos Aires 1900-1910". Entrepasados: Revista de História. Ano VI, 1997.

FRYDENBERG, Julio. História social del fútbol - del amateurismo a la profesionalización. Buenos Aires: Siglo Veintiuno, 2011.

GIGLIO, Sérgio Settani. A história política do Futebol Olímpico (1894-1988). São Paulo: Intermeios/FAPESP, 2018.

GIGLIO, Sérgio; SPAGGIARI, Enrico. 2010. "A produção das ciências humanas sobre futebol no Brasil: um panorama (1990-2009)". Revista de História, n. 163, p. 293-350.

HOLLANDA, Bernardo Buarque de. O fim do estádio-nação? Notas sobre a construção e remodelagem do Maracanã para a Copa de 2014. In: CAMPOS, Flávio; ALFONSI, Daniela. (Org.). Futebol - objeto das ciências sociais. São Paulo: Leya, p. 321-348, 2014.

KESSLER, Cláudia Samuel. Mais que Barbies e ogras: uma etnografia do futebol de mulheres no Brasil e nos Estados Unidos. Tese (Doutorado em Antropologia Social), IFCH-UFRGS, Porto Alegre, 2015. 
LOPES, Felipe Tavares Paes; HOLLANDA, Bernardo Borges Buarque de. "Ódio eterno ao futebol moderno": poder, dominação e resistência nas arquibancadas dos estádios da cidade de São Paulo. Tempo, v. 24, n. 2, p. 206-232, 2018.

MASCARENHAS, Gilmar. A bola nas redes e o enredo do lugar: uma geografia do futebol e seu advento no Rio Grande do Sul. Tese (Doutorado em Geografia), USP, São Paulo, USP, 2001.

MAZZONI, Tomaz. História do futebol no Brasil (1984-1945). São Paulo: Edições Leia, 1950.

MYSKIW, Mauro. Nas controvérsias da várzea: trajetórias e retratos etnográficos em um circuito de futebol da cidade de Porto Alegre. Tese (Doutorado em Ciências do Movimento), EEF - UFRGS, Porto Alegre, 2012.

PEREIRA, Leonardo. Footballmania: uma história social do futebol. Rio de Janeiro: Nova Fronteira, 2000.

PIMENTA, Rosangela. Desvendando o jogo: o futebol amador e a pelada na cidade e no sertão. Tese (Doutorado em Sociologia) - UFPE, Recife, 2009.

RODRIGUES FILHO, Mário. O negro no futebol brasileiro. 4a ed. Rio de Janeiro: Mauad, p. 2003 [1964].

SANTOS, João Manoel Casquinha Malaia. Revolução vascaína: a profissionalização do futebol e a inserção sócio-econômica de negros e portugueses na cidade do Rio de Janeiro (1915-1934). Tese (Doutorado em História Econômica) - USP, São Paulo, 2010.

SOARES, Antônio Jorge. História e a invenção de tradições no futebol brasileiro. In: HELAL, Ronaldo; SOARES, Antônio; LOVISOLO, Hugo. A invenção do país do futebol. Rio de Janeiro: Mauad, 2001, p. 77-99.

SPAGGIARI, Enrico. Família joga bola: constituição de jovens futebolistas na várzea paulistana. Tese (Doutorado em Antropologia Social) - FFLCH, USP, São Paulo, 2014.

TOLEDO, L. Henrique. Lógicas no futebol. São Paulo: Hucitec/FAPESP, 2002.

VELHO, Tulio Barreto. Gilberto Freyre e o futebol-arte. Revista USP, v. 62, p. 233-8, 2004.

ZELIZER, Viviana. "Circuits within Capitalism". In: NEE, Victor; SWEDBERG, Richard (eds). The Economic Sociology of Capitalism. Princeton: Princeton University Press, 2005, p. 289-321.

Recebido para publicação em: 17 abr. 2019.

Aprovado em: 18 abr. 2019. 